\title{
Ultrastructural and morphometrical analyses of Leydig and Sertoli cells in the testes of rats with hereditary polydactylism
}

\author{
H. Hojo ${ }^{1}$, H. Aoyama ${ }^{1}$, S. Tanaka ${ }^{2}$ and S. Teramoto ${ }^{1 *}$ \\ ${ }^{1}$ Institute of Environmental Toxicology, Uchimoriya-cho 4321, Mitsukaido-shi, Ibaraki, 303 Japan; \\ and ${ }^{2}$ Laboratory Animal Research Center, Institute of Medical Science, University of Tokyo, \\ Shirokanedai 4-6-1, Minato-ku. Tokyo, 108 Japan
}

\begin{abstract}
Rats of the polydactylous (PD) strain carry an autosomal recessive gene $p d$ that causes polydactylism in homozygotes ( $p d / p d)$. Male homozygotes are sterile owing to an abnormality of spermatogenesis. In the present study, Leydig and Sertoli cells of 12-week-old $p d / p d$ male rats were examined for ultrastructural alterations in an attempt to clarify the cause of the abnormal spermatogenesis. The relative volumes of the organelles were also determined with morphometry. Phenotypically normal pdl + males served as controls. No morphological or morphometrical abnormalities were noted in the Leydig cells. However, two different types of Sertoli cell were evident: light cells and dark cells. The incidence of the dark Sertoli cells in $p d l p d$ males was high $(27 \%)$ compared with that in $p d l+$ males $(6 \%)$. These dark cells contained quantities of lipid droplets in the cytoplasm and exhibited a significant increase in the relative volume of lipid droplets compared with the value for the light cells. The nuclei of the dark Sertoli cells were irregular in shape and were invaginated. These results suggest that dark Sertoli cells may have lower lipid metabolism, and in $p d / p d$ males, the high number of these dark Sertoli cells may be related to abnormal spermatogenesis.
\end{abstract}

\section{Introduction}

The polydactylous $(\mathrm{PD})$ strain of rats is characterized by having polydactylism in fore- and hind-limbs caused by an autosomal recessive gene $(p d)$ and has been established as a forcedheterogeneous inbred strain (Kaneda et al., 1989). Although female homozygotes can produce offspring when mated with phenotypically normal $p d /+$ males, male homozygotes never sire, even after mating with $p d l+$ or $+/+$ females.

Histological examination of the testes of $p d / p d$ males revealed degenerated spermatids at 9 weeks of age, and a decrease in tubular diameter, vacuolation of the nuclei of spermatocytes and spermatids, and occasionally multinucleated giant cells, at 12 weeks of age (Kaneda et al., 1990). However, no histological abnormality is noted in 3-and 6-week-old pd/pd males. If the time required before the abnormality in spermatogenesis becomes visible is taken into consideration, then, it is possible that the abnormal spermatogenesis in $p d / p d$ males is related to alterations in the Leydig and Sertoli cells rather than in the germ cells. Although when examined under a light microscope, the Leydig and Sertoli cells of $p d / p d$ males show no obvious differences from those of $p d l+$ males (Kaneda et al., 1990), it is not yet known whether these cells are functionally altered.

In the study reported here, testes from $p d / p d$ males were examined for possible ultrastructural alterations to the Leydig

*Correspondence.

Received 6 January 1995 and Sertoli cells that might be related to the malfunction of these cells. Morphometry of the organelles participating in the steroidogenesis was also conducted for evaluating functional conditions of these cells.

\section{Materials and Methods}

\section{Animals and treatments}

Polydactylous rats were maintained as an inbred strain by brother-sister matings between phenotypically normal $p d l+$ males and polydactylous $p d / p d$ females. The five $p d / p d$ males used in this study were 12 weeks of age; abnormality in spermatogenesis would be marked by this age (Kaneda $e t$ al., 1990). Five $p d l+$ males served as normal controls. The animals were housed in a room with controlled temperature $\left(24 \pm 2^{\circ} \mathrm{C}\right)$, humidity $(55 \pm 10 \%)$, ventilation ( 12 times per hour) and illumination ( $12 \mathrm{~h}$ per day). They were given a laboratory diet (solid feed MF, Oriental Yeast Co., Ltd, Tokyo) and tap water ad libitum.

\section{Preparation of the testes for observation by electron microscope}

After the animals were anaesthetized with ether, the testes were fixed by perfusion via the heart according to the method of Russell et al. (1986) with a $0.2 \mathrm{~mol}$ cacodylate buffer $\mathrm{l}^{-1}$ $(\mathrm{pH} 7.4)$ containing $2.5 \%(\mathrm{v} / \mathrm{v})$ glutaraldehyde and $2 \%(\mathrm{w} / \mathrm{v})$ paraformaldehyde (Karnovsky, 1965). In $p d / p d$ males, one testis frequently fails to descend into the scrotum (Kaneda et al., 


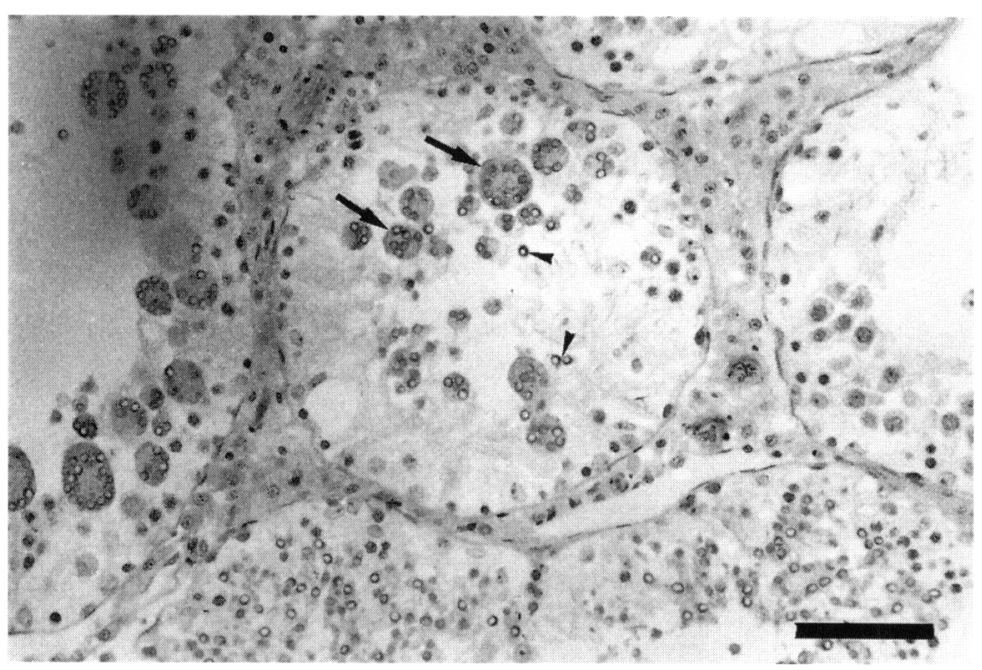

Fig. 1. The seminiferous tubules of a 12 -week-old $p d / p d$ male rat. Vacuolation (arrowheads) of the nuclei of the spermatocytes and spermatids and multinucleated giant cells (arrows) can be seen. Scale bar represents $80 \mu \mathrm{m}$. Reproduced, with permission, from Kaneda et al. (1990).

1990). This was the case in two of the $p d / p d$ males in this study; therefore, samples were taken only from the descended testis. The fixed testes were diced into cubes of $1 \mathrm{~mm}$ or less and placed into a 0.2 mol cacodylate buffer $\mathrm{l}^{-1}$ containing $5 \%(\mathrm{v} / \mathrm{v})$ glutaraldehyde and $4 \%(\mathrm{w} / \mathrm{v})$ paraformaldehyde for $2 \mathrm{~h}$ and post-fixed for $2 \mathrm{~h}$ in $2 \%(\mathrm{v} / \mathrm{v})$ osmium tetroxide at $4^{\circ} \mathrm{C}$ (Karnovsky, 1965). The tissues were then dehydrated, infiltrated and embedded in Epon 812. Ultrathin sections were made and double-stained with $1 \%(\mathrm{w} / \mathrm{v})$ uranyl acetate and $1 \%$ $(\mathrm{w} / \mathrm{v})$ lead citrate.

\section{Electron microscope observations}

The stained sections were examined under an electron microscope for alterations to the Leydig and Sertoli cells using (JEOL JEM-1200 EX II). In addition, since two different types of Sertoli cell with different electron densities (light and dark Sertoli cells) were identified in the seminiferous tubules, 200 Sertoli cells were selected at random from each animal and the percentage of dark Sertoli cells was determined.

\section{Morphometric analyses}

Twenty Leydig and 20 Sertoli cells were selected at random from each animal. The square lattice test system with 100 test points $100 \mathrm{~cm}^{-2}$ (Weibel et al., 1966; Andreis et al., 1989) was placed on the electron micrographs $(\times 20000)$ of the cells to determine differential counts of the points lying on mitochondria $\left(P_{\mathrm{m}}\right)$, smooth endoplasmic reticulum $\left(P_{\mathrm{s}}\right)$, lipid droplets $\left(P_{\mathrm{p}}\right)$ and cytoplasm $\left(P_{\mathrm{c}}\right)$. The total number of test points $\left(P_{\mathrm{T}}\right)$ was obtained from the following formula:

$$
P_{\mathrm{T}}=P_{\mathrm{m}}+P_{\mathrm{s}}+P_{1}+P_{\mathrm{c}}
$$

The relative volumes of mitochondria $\left(V v_{\mathrm{m}}\right)$, smooth endoplasmic reticulum $\left(V v_{s}\right)$ and lipid droplets $\left(V v_{1}\right)$ were calculated as follows:

$$
V v_{\mathrm{m}}=P_{\mathrm{m}} / P_{\mathrm{T}} ; V v_{\mathrm{s}}=P_{\mathrm{s}} / P_{\mathrm{T}} ; V v_{1}=P_{\mathrm{l}} / P_{\mathrm{T}}
$$

\section{Statistical analyses}

The incidence of the dark Sertoli cells and the volume density of organelles were analysed using Mann-Whitney's $U$ test.

\section{Results}

Changes to the seminiferous tubules of a 12-week-old pdlpd male as observed by Kaneda et al. (1990) using light microscopy are shown (Fig. 1).

\section{Observations on Leydig cells}

The nuclei of Leydig cells of $p d / p d$ males were oval and the cytoplasm contained mitochondria with tubular cristae, smooth endoplasmic reticula, lipid droplets and ribosomes (Fig. 2). The size and distribution of lipid droplets varied from cell to cell. These morphological features were comparable to those in $p d l+$ males. The relative volumes of mitochondria, smooth endoplasmic reticulum, and lipid droplets of $p d / p d$ and $p d l+$ males were similar (Table 1).

\section{Observations on Sertoli cells}

In $p d / p d$ males, dark Sertoli cells were frequently observed. In the light Sertoli cells, the border of the nucleus and cytoplasm was clear, and the cytoplasm contained mitochondria, smooth endoplasmic reticulum, lipid droplets, ribosomes and lysosomes (Fig. 3a). However, in the dark Sertoli cells, the nucleuscytoplasm border was indistinct (Fig. 3b). Nuclei were frequently irregularly shaped and contained invaginations and quantities of lipid droplets were present in the cytoplasm. Light and dark Sertoli cells were also observed in $p d l+$ male rats and their morphology was the same as that discussed above. However, there was a large difference in the frequency of dark Sertoli cells between the $p d / p d$ and the $p d l+$ male rats. In $p d / p d$ males, 


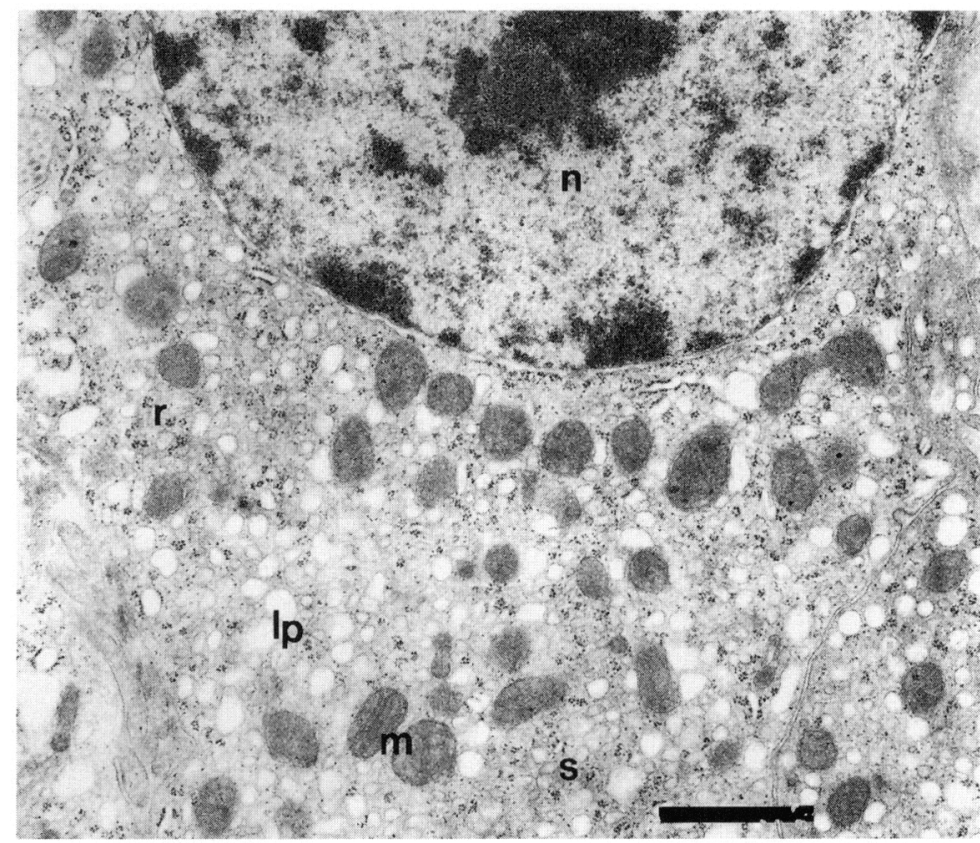

Fig. 2. A Leydig cell from the testis of a 12 -week-old $p d / p d$ male rat. The nucleus $(\mathrm{n})$ is oval and the cytoplasm contains mitochondria $(\mathrm{m})$ with tubular cristae, smooth endoplasmic reticulum (s), lipid droplets (lp), and ribosomes (r). Scale bar represents $1 \mu \mathrm{m}$.

Table 1. Relative volumes (\%) of mitochondria, smooth endoplasmic reticulum and lipid droplets in Leydig cells in the testes of 12-week-old rats of the polydactylous strain

\begin{tabular}{lcccc}
\hline Genotype & $\begin{array}{c}\text { Number of } \\
\text { rats }\end{array}$ & Mitochondria & $\begin{array}{c}\text { Smooth } \\
\text { endoplasmic } \\
\text { reticulum }\end{array}$ & $\begin{array}{c}\text { Lipid } \\
\text { droplets }\end{array}$ \\
\hline$p d / p d$ & 5 & $16.7 \pm 2.5$ & $8.9 \pm 1.2$ & $6.3 \pm 1.8$ \\
$p d l+$ & 5 & $13.8 \pm 1.6$ & $8.0 \pm 1.5$ & $8.3 \pm 4.8$ \\
\hline
\end{tabular}

$p d / p d$ : Homozygous rats; $p d l+$ : heterozygous rats.

Values are means $\pm \mathrm{sD}$.

dark Sertoli cells accounted for $27.2 \pm 10.0 \%(n=5)$ of the Sertoli cell population compared with $6.2 \pm 4.6 \%(n=5)$ in $p d l+$ males; this difference was statistically significant $(P \leq 0.01)$. The relative volumes of mitochondria, smooth endoplasmic reticulum and lipid droplets in the light Sertoli cells were comparable between $p d / p d$ and $p d /+$ male rats (Table 2). There was no significant difference in the relative volumes of mitochondria and smooth endoplasmic reticulum between light and dark Sertoli cells. However, the relative volume of lipid droplets was significantly higher in the dark Sertoli cells of $p d / p d$ male rats compared with that in light Sertoli cells. The incidence of dark Sertoli cells in $\mathrm{pd} / \mathrm{+}$ males was too low to collect a sufficient number for morphometric analysis.

\section{Discussion}

Polydactylous $p d l p d$ male rats are sterile owing to an abnormality of spermatogenesis. In the study reported here, Leydig and Sertoli cells of 12 -week-old $p d / p d$ males were examined for ultrastructural alterations by using $p d l+$ males of the same age as normal controls.

No changes in morphology or in relative volumes of organelles were noted in the Leydig cells of $p d / p d$ males when compared with the Leydig cells of $p d l+$ males of normal fertility. This result supports observations from our previous experiment (Kaneda ef al., 1990) in which no marked morphological alterations or reductions in mass were noted in the seminal vesicles and prostate glands of $p d / p d$ males.

However, dark Sertoli cells were present as well as the usual, light cells. In mice, rats, hamsters and humans, dark Sertoli cells are observed mainly in the testes of fetuses and neonates (Novi and Saba, 1968; Solari and Fritz, 1978; Wartenberg, 1978; Yasuda et al., 1986; Miething, 1989). These dark Sertoli cells are considered to take part in pre-spermatogenesis, during which the differentiation of the gonocytes is accelerated (Wartenberg, 1978; Yasuda et al., 1986). The dark Sertoli cells then decrease in number with increasing age after birth (Solari and Fritz, 1978; Miething, 1989). The presence of dark Sertoli cells in the seminiferous tubules of sexually mature males has also been reported in pigs, cattle, and humans. In boars and bulls, although the metabolic states of the dark Sertoli cells and the light Sertoli cells differ (Osman, 1978; BielanskaOsuchowska and Sysa, 1981), the physiological significance of these dark cells is unknown. Dark Sertoli cells have been found in humans with testicular feminization, and degenerative alterations such as folded nuclear membranes, dilated agranular endoplasmic cisternae and swollen mitochondria have been observed (Justrabo et al., 1978; Millonig et al., 1978). Patients with testicular feminization are sterile. However, the occurrence 

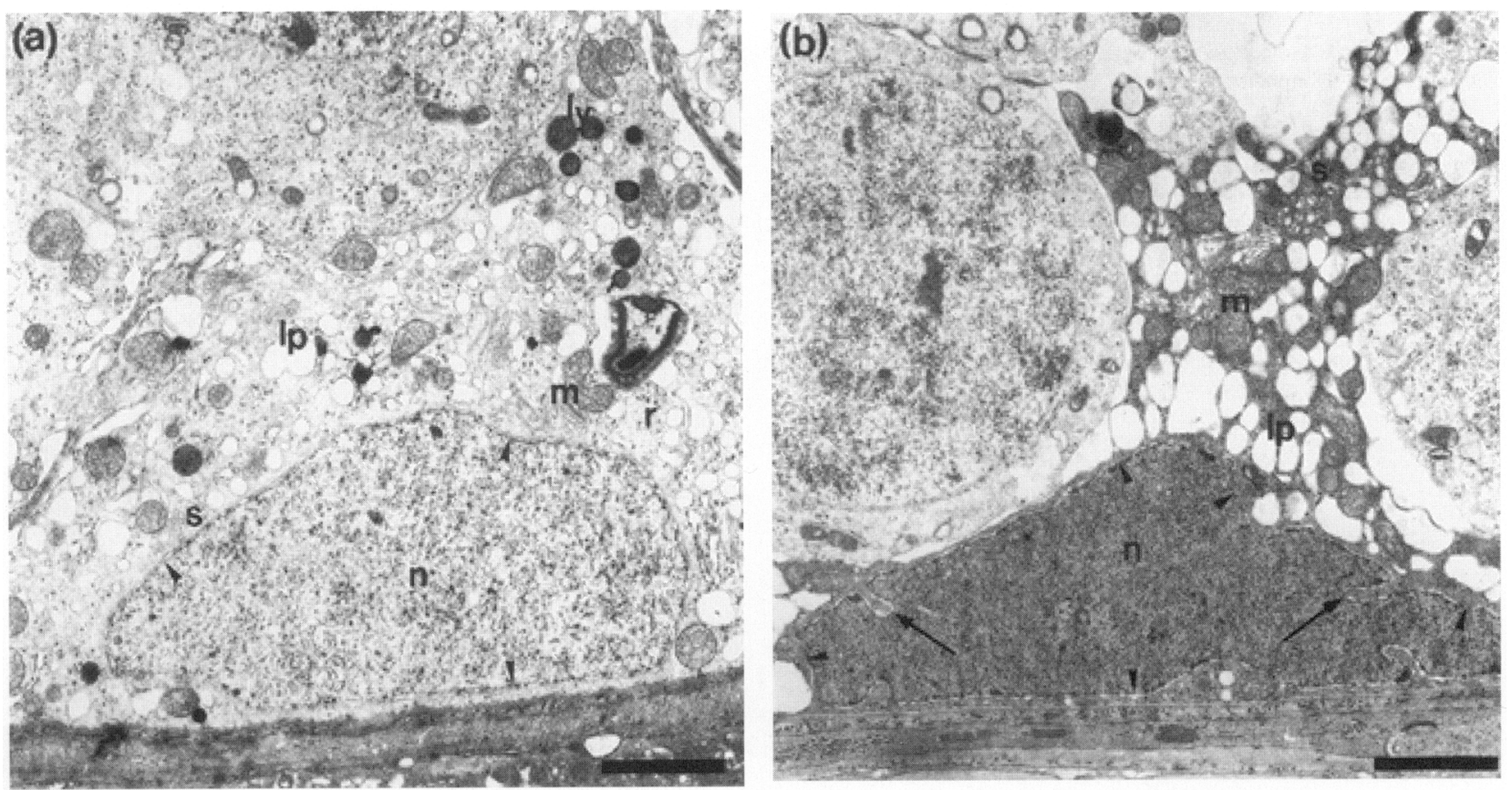

Fig. 3. Sertoli cells from the testis of a 12-week-old pdlpd male rat. (a) A light Sertoli cell showing the border (arrowheads) of the nucleus (n) and clear cytoplasm. Mitochondria (m), smooth endoplasmic reticulum (s), lipid droplets (lp), ribosomes ( $\mathrm{r}$ ) and lysosomes (ly) are distributed throughout the cytoplasm. (b) A dark Sertoli cell showing a dense nucleus (n) and cytoplasm. The nucleus-cytoplasm border (arrowheads) is indistinct. The nucleus is irregular in shape and contains invaginations (arrows). Many lipid droplets (lp) are seen in the cytoplasm. Scale bars represent $2 \mu \mathrm{m}$.

Table 2. Relative volumes (\%) of mitochondria, smooth endoplasmic reticulum and lipid droplets in Sertoli cells in the testes of 12 -week-old rats of the polydactylous strain

\begin{tabular}{lccccc}
\hline Genotype & $\begin{array}{c}\text { Number } \\
\text { of rats }\end{array}$ & $\begin{array}{c}\text { Type of } \\
\text { Sertoli cell }\end{array}$ & Mitochondria & $\begin{array}{c}\text { Smooth } \\
\text { endoplasmic } \\
\text { reticulum }\end{array}$ & $\begin{array}{c}\text { Lipid } \\
\text { droplets }\end{array}$ \\
\hline$p d / p d$ & 5 & Light & $9.7 \pm 1.2$ & $3.5 \pm 1.3$ & $12.7 \pm 2.4$ \\
$p d /+$ & 5 & Dark & $7.8 \pm 1.8$ & $2.3 \pm 0.5$ & $31.9 \pm 1.8^{\text {a }}$ \\
& Light & $10.1 \pm 2.5$ & $2.6 \pm 0.3$ & $13.8 \pm 3.0$ \\
\hline
\end{tabular}

Values are means $\pm \mathrm{sD}$.

aignificantly different from light Sertoli cells of $p d / p d$ and $p d l+$ males $(P \leq 0.01)$.

of these abnormal dark cells is not considered to be the cause but a result of sterility (Justrabo et al., 1978; Millonig et al., 1978).

The present study demonstrates a low incidence of dark Sertoli cells in 12-week-old $p d l+$ male rats. Therefore, the presence of dark Sertoli cells could be a common phenomenon in adult rats. However, the incidence of dark Sertoli cells was much higher in $p d / p d$ males than in $p d l+$ males. In $p d / p d$ males, these cells had morphological alterations in the nuclei and the cytoplasm contained quantities of lipid droplets, suggesting decreased lipid metabolism. These results suggest that in $p d / p d$ male rats a high incidence of functionally altered Sertoli cells may be related to abnormal spermatogenesis.

\section{References}

Andreis PG, Rebuffat P, Belloni AS, Neri G, Cavallini L, Gottardo G, Mazzocchi G, Coi A, Malendowicz LK and Nussdorfer GG (1989) Stereological and function investigations on isolated adrenocortical cells: zona fasciculata/reticularis cells of chronically ACTH-treated rats Cell and Tissue Research 258 43-5I

Bielanska-Osuchowska Z and Sysa PS (1981) Ultrastructure of the bull seminiferous tubule supporting cells with special consideration of the cell junctions Anatomia, Histologia, Embryologia 10 370-387

Justrabo E, Cabanne F, Michiels R, Bastien H, Dusserre P, Pansiot F and Cayot F (1978) A complete form of testicular feminisation syndrome; a light and electron microscopy study Journal of Pathology 126 165-171

Kaneda M, Teramoto $S$ and Shirasu $Y$ (1989) Anatomical features associated with preaxial duplication (pd): a recessive mutation in the rat Teratology 40 77-84

Kaneda M, Hojo H, Aoyama H, Teramoto S and Shirasu Y (1990) Male infertility in the hereditary polydactyly (PD) rat Laboratory Animal Science 40 379-383 
Karnovsky MJ (1965) A formaldehyde-glutaraldehyde fixative of high osmolality for use in electron microscopy The Journal of Cell Biology 27 137A

Miething A (1989) Morphological studies on prespermatogonia and pre-Sertoli cells in the testes of 6- to 11-day-old golden hamsters Anatomy and Embryology 179 503-510

Millonig G, Morano E, Bollero E, Vecchietti G and Zanoio L (1978) Ultrastructural study of gonads in the complete and incomplete feminization syndrome Gynecologic and Obstetric Investigation 9 16-31

Novi AM and Saba P (1968) An electron microscopic study of the development of rat testis in the first 10 postnatal days Zeitschrift für Zellforschung 86 $313-326$

Osman DI (1978) On the ultrastructure of modified Sertoli cells in the terminal segment of seminiferous tubules in the boar Journal of Anatomy 127 $603-613$
Russell LD, Sprando RL, Killinger J, Wilzcynski S, Thomassen RW, Tolzmann G and Burt AM (1986) A simple technique for perfusion of the rat testis through the heart Journal of Andrology $732 \mathrm{P}$

Solari AJ and Fritz IB (1978) The ultrastructure of immature Sertoli cells. Maturation-like changes during culture and the maintenance of mitotic potentiality Biology of Reproduction 18 329-345

Wartenberg H (1978) Human testicular development and the role of the mesonephros in the origin of a dual Sertoli cell system Andrologia 10 $1-21$

Weibel ER, Kistler GS and Scherle WF (1966) Practical stereological methods for morphometric cytology Journal of Cell Biology 30 23-38

Yasuda Y, Konishi H, Matuso T and Tanimura T (1986) Accelerated differentiation in seminiferous tubules of fetal mice prenatally exposed to ethinyl estradiol Anatomy and Embryology 174 289-299 